\title{
COMPARISON OF ARTIFICIAL INSEMINATION WITH NATURAL MATING TECHNIQUE IN RHESUS MONKEYS, MACACA MULATTA
}

\author{
DIANE S. FORDNEY SETTLAGE,* S. SWAN AND \\ A. G. HENDRICKX \\ National Center for Primate Biology, University of California, Davis, California
}

(Received 18th Fuly 1972)

Efficient artificial insemination (A.I.) is a necessary adjunct to captive breeding of the non-human primate. In addition to overcoming natural mating problems of mate rejection and trauma, A.I. has the advantages of selective breeding for desirable laboratory animal traits and exact knowledge of conception factors important in studying the early reproductive process.

Minimal data on A.I. in the non-human primate are available. Bennett (1967) described the insemination of three squirrel monkeys following HCG-induced ovulation with recovery of fertilized eggs. Van Pelt (1970) recorded intraperitoneal insemination with conception and delivery in three out of eight rhesus monkeys. Dede \& Plentl (1966) inseminated for 8 mid-cycle days with a pregnancy rate of $13 \%$ with induced ovulation and $12 \%$ for presumed spontaneous ovulation. These rates equalled those of natural mating. In Macaques, Leverage, Valerio \& Schultz (paper presented at Session of Am. Ass. Lab. Anim. Sci. in 1971 ) found a $13 \%$ natural mating conception rate, a $4 \%$ vaginal A.I. conception rate, a $21.2 \%$ intracervical A.I. conception rate and a $20.6 \%$ intrauterine A.I. conception rate.

For the present study, twenty females chosen at random from the breeding colony were assigned in groups of four to each of five males. Forty additional females and the remaining colony males bred during the time of this study by standard natural mating techniques formed the control group. All animals in the colony were highly fertile and all females had a history of at least one conception for each six menstrual cycles in which mating occurred. For both study groups, exposure to spermatozoa (a term used here to imply either A.I. or natural mating as appropriate) was begun in the menstrual cycle following the first menses after weaning of the females' most recent infant.

The females undergoing A.I. were inseminated on Days 10, 12 and 14 of the first cycle. The second and third cycle insemination days were adjusted to provide sperm exposure every other day from 2 days before the next anticipated mid-cycle to 14 days before the next anticipated menses as calculated from each animal's preceding menstrual cycle lengths. The females were palpated regularly till the presence or absence of pregnancy was confirmed. All females

\footnotetext{
* Present address: Department of Obstetrics and Gynecology, Division of Reproductive Biology, University of Southern California, Los Angeles, California.
} 
were inseminated for three consecutive menstrual cycles unless conception occurred earlier.

The technique of insemination consisted of collection of ejaculates by the electroejaculation technique of Mastroianni \& Manson (1963) into an adapted 5 -ml syringe with a flanged top and a stoppered bottom. The syringe was placed into the vagina of a female held in a 'tail-up' position, the ejaculate was expelled against her cervix, and the female was then immediately released into her cage.

The females in the natural mating control group were kept in the same cage with randomly assigned males for $2 \mathrm{hr}$ on Day 10 or 11 for each of three consecutive cycles, unless conception occurred earlier.

Table 1. Conceptions resulting from natural mating and artificial insemination in rhesus monkeys

\begin{tabular}{|c|c|c|}
\hline & Natural mating & Artificial insemination \\
\hline \multirow{4}{*}{$\begin{array}{l}\text { No. of males } \\
\text { No. of females } \\
\text { No. of cycles of exposure to } \\
\text { spermatozoa } \\
\text { No. of conceptions } \\
\% \text { females conceiving } \\
\% \text { conceptions to cycles of } \\
\text { exposure to spermatozoa }\end{array}$} & $\begin{array}{r}5 \\
40\end{array}$ & $\begin{array}{r}5 \\
20\end{array}$ \\
\hline & 96 & 47 \\
\hline & $\begin{array}{l}16 \\
40 \cdot 0\end{array}$ & $\begin{array}{l}10 \\
50.0\end{array}$ \\
\hline & $16 \cdot 6$ & $21 \cdot 3$ \\
\hline
\end{tabular}

Period: February to September 1971.

Table 2. The percentage of total conceptions occurring for rhesus females during each cycle of exposure to spermatozoa

\begin{tabular}{l|c|c}
\hline Exposure cycle & Natural mating & A.I. \\
\cline { 2 - 3 } First & $27 \cdot 5$ & 25 \\
Second & $5 \cdot 0$ & 15 \\
Third & 7.5 & 10 \\
\hline Total & 40 & 50 \\
\hline
\end{tabular}

Data obtained from the A.I. group were correlated with each animal's past history and with differences from the natural mating study group. Where applicable, significance of difference was calculated by the $\chi^{2}$ and Student's $t$ tests.

Table 1 contains the total conceptions and the relationship of menstrual cycles in which exposure to spermatozoa occurred to conceptions for the A.I. group and natural mating group. There was no significant difference between the groups. Additionally, there was no difference between the groups in the outcome of the pregnancies.

Table 2 shows that the highest number of conceptions occurred in the first exposure cycle for both study groups $(P<0.01)$ and there was no significant 
difference between the A.I. and the naturally mated groups. Conceptions in the second and third cycles of exposure were higher for the A.I. group $(P<0.05)$. Analysis of menstrual cycle lengths and their standard deviation for each female studied revealed that the A.I.-group animals with long, short or variable cycles conceived in the second or third cycle of exposure but that similar animals bred by standardized natural mating techniques did not.

The past fertility of the females studied was evaluated by calculation of the percentages of the total number of menstrual cycles in which mating occurred to the total number of conceptions for each female. By this criteria, those females conceiving during the first cycle of exposure either to natural mating or to A.I. were more fertile than those females conceiving later or not at all $(P<0.01)$. Thus, those females conceiving during this study on the first cycle of exposure to spermatozoa had a significantly higher percentage of past cycles in which mating occurred resulting in pregnancy.

Table 3. Comparison of reproductive performance in rhesus monkeys during artificial insemination with their natural mating performance

\begin{tabular}{l|c|c}
\hline & Past natural mating & Current A.I. \\
\hline $\begin{array}{l}\text { Males } \\
\text { No. of females exposed to sperm- }\end{array}$ & 77 & \\
$\quad$ atozoa & & 20 \\
$\begin{array}{l}\text { No. of cycles during which } \\
\text { females were exposed to sperm- }\end{array}$ & 150 & 47 \\
atozoa & 34 & 10 \\
No. of conceptions & 23 & 21 \\
$\%$ females conceiving & 44 & 50 \\
conceptions to cycles of expos- & & \\
ure to spermatozoa & & 47 \\
Females & 83 & 10 \\
No. of cycles during which females & 20 & 21 \\
were exposed to spermatozoa & 24 & \\
No. of conceptions & & \\
conceptions to cycles of expos- & & \\
\hline
\end{tabular}

Table 3 compares the overall performance of the A.I. study animals with that from their previous natural mating to identify any possible change in conceptions due to factors of time, alternative mates and sperm exposure procedures. No such differences were found.

Seasonal variations in fertility reported by others (Hafez, 1970; Dede \& Plentl, 1966) were seen in this study. They were equivalent both for the naturally mated and for the A.I. groups. February, March, April and September (high fertility months in previous studies) showed a conception rate which was twice that of the previously reported low fertility months of May, June, July and August.

Although data on semen volumes and sperm counts were obtained on all ejaculates used for A.I., no correlation of these could be made with conceptions.

Compared with other reports on conceptions resulting from natural mating 
and A.I., the results of both methods were excellent for this colony of rhesus monkeys. Natural mating and A.I. proved to be equally effective. The natural fertility of animals used for breeding appears to be a major factor in production of high conception rates and thus indicates that animals included in breeding colonies should be carefully selected.

Similarly, higher conception rates in the A.I. group during the second and third exposure cycles, when insemination days were adjusted to each female's cycle, indicates that standard mid-cycle mating may not be adequate for animals with variable or unusually long or short menstrual cycles. In the human, it is established that the postovulatory phase of the menstrual cycle is a relatively constant 14 days regardless of the total cycle length. This study offers evidence of a similar pattern in the rhesus monkey.

The seasonal decrease in conception rates was unaffected by changes in the timing of A.I. No significant seasonal oligospermia or abnormal sperm behaviour was noted with the males used. Additional evidence is therefore presented to show that the cause of seasonal conception decline is due to anovulation, as was recently suggested by Riesen, Meyer \& Wolf (1971).

A simple technique of artificial insemination has been shown to be at least as effective as natural mating in highly fertile animals. Evidence is also presented that conceptions are higher when exposure to spermatozoa is timed to coincide with each female's menstrual cycle variations rather than with her mid-cycle alone.

The authors wish to acknowledge the technical assistance of Mrs Leilani Sparke, Mr Bill Virgen, Mr Wanless Hatcher, Mr Maurice Anderson, Mr James Batchelor and Mr Bruce Orser. This research was supported by NIH Grant RR-00169. NIH Contract 71-2088 and NIH Health Sciences Advancement Award RR 06138.

\section{REFERENCES}

BENNETt, J. P. (1967) Artificial insemination of the squirrel monkey. F. Endocr. 37, 473.

Dede, J. \& Plentl, A. (1966) Induced ovulation and artificial insemination in a rhesus colony. Fert. Steril. 17, 757.

HAFEZ, E. S. (1970) Reproduction and breeding techniques for laboratory animals, p. 313. Lea \& Febiger, Pa.

Mastroianni, L., JR \& Manson, W. A., JR (1963) Collection of monkey semen by electroejaculation. Proc. Soc. exp. Biol. Med. 112, 1025.

Riesen, J., Meyer, R. \& Wolf, R. (1971) The effect of season on occurrence of ovulation in the rhesus monkey. Biol. Reprod. 5, 111.

Van Pelt, L. F. (1970) Intraperitoneal insemination of Macaca mulatta. Fert. Steril. 21, 159. 